\title{
FUNGSI MUSIK DALAM RITUAL TIBAN \\ DI DESA PURWOKERTO KECAMATAN NGADILUWIH \\ KABUPATEN KEDIRI
}

\author{
Viesta Agustina, Muhammad Nur Salim* \\ Program Studi Seni Karawitan Fakultas Seni Pertunjukan \\ Institut Seni Indonesia (ISI) Surakarta \\ Email: viestaa8@gmail.com
}

\begin{abstract}
Abstrak
Artikel dengan judul "Fungsi Musik dalam Ritual Tiban di Desa Purwokerto Kecamatan Ngadiluwih Kabupaten Kediri" difokuskan pada persoalan bentuk ritual Tiban, sajian musik ritual Tiban dan fungsi musik ritual Tiban. Hasil penelitian menunjukkan bahwa ritual Tiban diselenggarakan ketika musim kemarau panjang dengan tujuan meminta hujan melalui adu cambuk oleh para pelaku atau yang disebut petiban. Ritual Tiban dipercaya masyarakatnya dapat mendatangkan hujan dengan media darah yang menetes di atas tanah. Musik Tiban mempunyai beberapa motif dalam struktur tabuhan yang menjadi ciri khas dalam musik Tiban. Musik Tiban memiliki fungsi penting di dalam ritual Tiban. Fungsi musik tersebut diantaranya fungsi pengungkapan emosional, estetika, komunikasi, reaksi jasmani, pengesahan lembaga sosial dan upacara keagamaan, kesinambungan budaya, dan pengintegrasian masyarakat.
\end{abstract}

Kata Kunci : Ritual Tiban, musik Tiban, fungsi musik

\begin{abstract}
$\underline{\text { Abstract }}$
The article entitled "The Function of Music in Tiban Rituals in Purwokerto Village, Ngadiluwih District, Kediri Regency" focused on the issue of Tiban ritual forms, Tiban ritual music performance and the function of Tiban ritual music. The results showed that the Tiban ritual was held during the long dry season with the aim for asking for rain through whipping by the perpetrators or what is called petiban. The people believe that the Tiban ritual can bring rain by means of media of blood dripping on the ground. Tiban music has several motifs in the wasp structure that characterizes it. Tiban music has an important function in Tiban rituals. The functions of music include the function of emotional expression, aesthetics, communication, physical reaction, legalization of social institutions and religious ceremonies, cultural sustainability, and community integration.
\end{abstract}

Key words: Tiban ritual, Tiban music, Functions of Music

*Penulis Korespondensi Program Studi Seni Karawitan Fakultas Seni Pertunjukan Institut Seni Indonesia (ISI) Surakarta Email: denmassalim88@gmail.com 


\section{Pengantar}

Masyarakat Jawa sudah mengenal adanya kepercayaan sebelum masuknya agama Hindu Budha dan juga Islam. Masuknya Islam di Jawa memiliki pengaruh terhadap sistem kepercayaan masyaraktnya dengan wujud sinkritisme. Sinkritisme memuat kepercayaan animisme yang tertuang di dalam bentuk ritus yang bertujuan agar terhindar dari kekuatan roh halus yang dianggap jahat dan mengganggu keteraturan sehingga ekuilibrium dalam masyarakat dapat terjaga (Kastolani and Yusuf 2016, 59). Kekuatan tersebut dapat berasal dari roh atau jiwa pada benda-benda, tumbuhantumbuhan, hewan dan juga pada manusia sendiri. Untuk mengendalikan dan menyeimbangkan kekuatan-kekuatan tersebut diperlukan suatu upacara ritual. Mereka meminta berkah pada Yang Maha Kuasa dan meminta agar roh jahat tidak mengganggu.

Upacara ritual dapat dibagi dua kata yaitu upacara dan ritual. Upacara adalah suatu kegiatan sekelompok orang yang memiliki tahapan diatur dengan tujuan acara. Sedangkan ritual adalah berhubungan terhadap keyakinan dan kepercayaan spiritual dengan tujuan tertentu. Upacara ritual dapat diartikan sebagai peranan yang dilakukan oleh komunitas pendukung suatu agama, adatistiadat, kepercayaan, atau prinsip, dalam rangka pemenuhan kebutuhan akan ajaran atau nilai-nilai budaya dan spiritual yang diwariskan turun-temurun oleh nenek moyang mereka. Upacara ritual dalam sudat pandang Victor W. Turner dimaknai sebagai sebuah fenomena sosial dari suatu budaya tertentu yang terbangun melalui adanya interaksi sosial di dalam periode tertentu (Turner 1969).

Upacara ritual menjadi suatu peristiwa umum di dalam masyarakat yang masih memepercayai hal-hal yang bersifat mistis. Kepercayaan mistis ini yang kemudian dimanifestasikan ke dalam sebuah upacara ritual ataupun ekspresi seni tertentu (Sumardjo 2006, 177). Salah satu bentuk upacara yang masih terjaga keberlangsungannya adalah upacara ritual Tiban di Desa Purwokerto, Kecamatan Ngadiluwih, Kabupaten Kediri. Warga Desa Purwokerto menyelenggarakan upacara ritual Tiban dengan tujuan untuk meminta kepada Yang Maha Kuasa. Tiban adalah ritual meminta hujan dilaksanakan pada saat terjadi kemarau panjang. Istilah Tiban berasal dari kata dasar tiba dalam bahasa Jawa berarti jatuh. Tiban mengandung arti timbul sesuatu tidak diduga, semula tiada menjadi ada. Dalam konteks tiada menjadi ada yaitu hujan yang turun saat pelaksanaan Tiban. Ritual dilaksanakan pada bulan Sura di tempat penjualan sapi di Desa Purwokerto.

Ritual Tiban dilakukan dengan cara mengadu kekuatan fisik dengan menggunakan pecut. Pecut terbuat dari lidi aren dipintal dengan ukuran sebesar genggaman tangan laki-laki dewasa. Lidi aren terkenal dengan kelenturannya serta tidak mudah rusak berbeda dengan lidi daun kelapa yang cenderung kaku dan mudah patah. Selain lentur, ujung lidi aren jika dicambukkan membuat luka cukup dalam dan bisa mengeluarkan banyak darah. Pecut digunakan tidak hanya satu melainkan terdapat 60 pecut sesuai jumlah peTiban. PeTiban adalah istilah untuk pemain Tiban. Ritual Tiban menjadi ajang mengadu ilmu ketahan fisik dan kesaktian sambil menari-nari. PeTiban saling memecut dengan hitungan ditentukan oleh wasit atau sesepuh Tiban atau dalam istilah lokal disebut dengan Plandang. Masyarakat percaya bahwa dengan adanya Pecut Tiban serta darah yang keluar dari tubuh peTiban terjadilah hujan. Semakin banyak darah keluar dari tubuh, semakin deras hujan turun. Kepercayaan di luar rasional tentang kekuatan magi ini yang mendasari sebuah asumsi bahwa ketika sebuah ritual dilakukan secara benar maka dampak alaminya seperti yang telah ditetapkan akan benar-benar terjadi. Magi mendasari 
hokum yang bersifat impersonal tetap dan universal tentang ritual hujan, dan jika ini dilakukan dengan benar maka hujan benar-benar akan turun (Ismail 2012, 12)

Pelaksanaan upacara ritual bergantung pada struktur pelaksanaan yang terwujud di dalam rangkaianrangkaian aktivitas tertentu mulai dariawal dan akhir (Geertz 1992, 32). Upacara ritual Para pemain, sesepuh serta perangkat desa diarak dari Balai Desa menuju ke Pasar Sapi Rajakaya Purwokerto sambil arakarakan berjalan, sesepuh menaburi bunga disepanjang jalan menuju lokasi, sesepuh sambil memikul tumpeng sebagai syarat dalam Tiban. Semua pelaku terdiri dari para sesepuh, pemain, perangkat desa naik ke panggung beserta persyaratan ritual Tiban seperti Tumpeng, alat-alat musik serta pecut untuk melakukan ritual Tiban. Pelaku Tiban tidak hanya berasal dari Desa Purwokerto atau dari Kediri melainkan dari Tulungagung, Blitar, Trenggalek, karena pada daerah-daerah tersebut terdapat Tiban. Pelaku adalah orang lakilaki dewasa antara 20 - 40 tahun. Penonton juga bisa menjadi salah satu peTiban. Penonton diperbolehkan menjadi peTiban jika umur dan fisik dirasa cukup untuk menjadi peTiban. Keterlibatan penonton bertujuan untuk lebih memeriahkan ritual Tiban. Ritual Tiban diikuti oleh 60 orang dibagi dalam 30 pelaku, setiap pelaku terdiri dari 2 orang, masing-masing pelaku diberi waktu 2-3 menit untuk melakukan pecutan dengan lagu berbeda. Pelaku Tiban yang berada di atas panggung, selain peTiban masih ada kelompok lain yaitu penabuh gamelan. Penabuh gamelan pada ritual Tiban pelaku wajib ada pada saat ritual Tiban. Penabuh gamelan tersebut terdiri dari seorang pengendang, 4 orang penabuh thonthongan bermain bergantian, seorang penabuh kethuk, seorang penabuh gong, dan penyanyinya. Semua penabuh dan $p e$ Tiban dilakukan oleh laki-laki.

Plandang Tiban mulai berdoa sebelum memberi arahan kepada peTiban berapa kali pelaku harus memecut, kemudian para petiban meminum banyu kembang. Banyu kembang secara harfiah berarti air diisi dengan berbagai macam bunga. Dipercayai dengan peTiban meminum banyu kembang, mereka terhindar dari marabahaya. Aturan-aturan Tiban, peTiban diperbolehkan memecut sebanyak 5 kali. Sasaran pecutan dilarang untuk memecut kepala dan kaki. Batasan pecutan dari bawah leher hingga atas pusar.

Terdapat 10 pecutan dalam satu ronde ritual Tiban yang dilakukan oleh 2 orang peTiban. Dua orang peTiban dalam satu ronde diiringi dengan 1 lagu. Pecutan ini pada akhirnya menentukan waktu jalannya ritual. Ritual Tiban terdapat 30 ronde yang diiringi lagu. Setiap ronde memiliki lagu yang berbeda. Lagu-lagu yang digunakan adalah Caping Gunung, Ngidham Sari, Yen Ing Tawang, Tak Enteni, Luntur, Srihuning, Gubug Asmara, Sesideman, Dadi Ati, Wuyung, Kadhung Tresna, Ngelamuning Ati, Ngelam-elami, Taman Sari, Setya Tuhu, Ireng Manis, Kangen, Ngujiwat, Pawelingku, Pegat Tresna, Jenang Gula, Atiku Lega, Aja Lamis, Kelinci Ucul, Kutha Blitar, Sandhang Pangan, Piye Janjine, Pamitan, Meh Rahina, Nawala. Setiap satu lagu digunakan satu ronde pada ritual Tiban yang menentukan waktu jalannnya ritual, dan musik mempunyai fungsi yang indikatornya tertuang dalam 10 pecutan.

Berdasarkan bentuk ritual Tiban yang memuat unsur-unsur pendukung dan tatacara pelaksanaannya, dapat digolongkan sebagai sebuah peristiwa budaya. Di dalamnya memuat simbolsimbol dengan makna-makna tertentu sehingga peristiwa ini dapat masuk pada ranah pertunjukan. Pertunjukan diangap sebagai kesatuan dari tindakan manusia dalam bentuk ritual, permainan, olah raga, hiburan populer, seni pertunjukan dan pertunjukan kehidupan sehari-hari (Schechnesr 2002, 2). Salah satu unsur seni yang terdapat di dalam ritual Tiban adalah musik. Sajian musik yang digunakan selalu sama berupa motif tertentu pada alat atau 
isntrumen musik yang digunakan.

Keunikan dari musik dalam Tiban ini adalah diharuskan menggunakan thonthongan sebagai alat musik utama. Meski demikian, thonthongan bukan sebagai pemimpin jalannya sajian. Pemimpin jalannya sajian adalah kendang. Kendang mengawali sajian ritual, dari semua instrumen hingga peTiban. Sebelum kendang mengawali permainannya, pemusik dan peTiban tidak ada yang memulai ritual. PeTiban harus mengikuti irama musik. Musik dalam ritual Tiban penting bagi pelaku karena hal tersebut merupakan salah satu syarat ritual Tiban. Musik sebagai bagian dari ritual, memberikan rasa percaya diri bagi pelaku terhadap setiap instrumen. Hal ini menjadi satu indikasi bahwa musik mempunyai kaitan dengan jalannya sajian ritual. Peristiwa tersebut melatarbelakangi penelitian terkait dengan struktur dan fungsi musik dalam Ritual Tiban di Desa Purwokerto Kecamatan Ngadiluwih Kabupaten Kediri.

\section{Bentuk Ritual Tiban}

Ritual menjadi sebuah perilaku 'peribadahan' berupa ekspresi simbolik yang terbangun atas bahasa gerak dan pemikiran religius. Perilaku ini kemudian menjadi keajaiban permanen (sakral) yang dijalankan secara terus menerus oleh masyarakat yang meyakininya (Koentjaraningrat 1997, 81). Tiban menjadi bagian kebudayaan masyarakat Jawa Timur, terutama pada daerah Kediri, Blitar, Tulungagung dan Trenggalek. Pada ritual, masyarakat menyiksa diri dengan Pecut yang telah disiapkan dan masyarakat berjemur dipanas terik. Ritual Tiban sebagai kepercayaan bagi masyarakat Purwokerto bertujuan untuk memanggil kekuatan supranatural yang mendatangkan hujan. Mereka percaya bahwa semakin banyak darah yang mengalir maka semakin deras hujan turun. Ritual dan seluruh keyakinan masyarakat ini telah berlangsung secara turun-temurun. Penyelenggaraan ritual beserta pembacaan narasi-narasi yang berhubungan dengan mitos, drama dan pertunjukan inilah yang kemudian membentuak suatu teks transformatif sehingga memungkinkan masyarakat untuk dapat mengalami warisan budaya tersebut (Bruner and Turner 1986, 7).

Upacara ritual selalu terkait dengan komponen-komponen yang membangunnya, yaitu tempat upacara, waktu upacara, benda-benda dan alat-alat upacara, dan orang-orang yang melakukan dan memimpin upacara (Koentjaraningrat 1990). Pada tahun 2000-an pelaku ritual Tiban diperbolehkan membawa alat pecut sendiri-sendiri, hal itu disebabkan karena pelaku Tiban tidak hanya dari daerah sekitar Purwokerto saja, dan tidak sedikit pelaku Tiban tersebut menaruh dendam kepada lawan mainnya ada beberapa pelaku yang menaruh silet pada pecut. Hal seperti silet tersebut dilakukan karena peTiban dari desa lain dendam dengan peserta sebelumnya yang berpartisipasi. Fungsi lain dari Pecut adalah sarana penebus dosa dalam ritual Tiban.

Prosesi ritual memuat perilaku'bolakbalik' antara perilaku di luar dan yang akan dimunculkan di dalam pertunjukan, antara perilaku penting (seperti cerita, perilaku wajib, doa dan lain-lain) serta detail teknik yang membentuk pertunjukan itu sebagai pertunjukan (performance as performance) (Schechner 1985, 54). Di dalam ritual Tiban terdapat prosesi yang wajib diperhatikan untuk dapat melaksanakan ritual. Melaksanakan ritual harus memperhatikan waktu, berbeda dengan ritual-ritual yang dilakukan pada malam hari, ritual Tiban dilakukan pada siang hari yang diyakini menyiksa diri untuk tercapainya maksud dari ritul Tiban selain melakukan pecutan. Pelaksanaan ritual Tiban dimulai pada pukul 08.00 WIB hingga pukul 12.00 WIB. Pemilihan waktu tersebut dikarenakan pergantian waktu pagi ke siang dimana matahari mulai terik yang dipercaya dengan adanya sengatan matahari maka tubuh terbakar dari perwujudan 
menyiksa diri selain melakukan pecutan. Pelaksanaan Tiban pada 1 suro menjadi permohonan kepada yang maha kuasa untuk diturunkannya hujan. Jika dalam waktu 6-7 bulan tidak turun hujan maka ritual akan dilaksanakan. Pada tahun 2000an, ritual ini dilakukan pada bulan Suro. Dilakukan pada bulan Suro, tidak bisa sembarangan memilih waktu untuk melakukan ritual Tiban yaitu pada siang hari karena diyakini dengan adanya terik matahari permohonan permintaan penurunan hujan akan cepat dikabulkan. Tiban juga mempunyai tempat ritual, yaitu di pasar sapi Rajakaya yang dijadikan tempat ritual Tiban sejak dahulu.

Selain waktu dan tempat, terdapat alur sajian dalam prosesi ritual. Alur sajian dibagi menjadi 3 yaitu pembukaan, Ritual Tiban dibuka dengan acara arakarakan dari kantor desa menuju tempat ritual yaitu Pasar Rajakaya. Arak-arakan tersebut diikuti oleh seluruh pemain ritual dan sesepuh Tiban serta plandang. Para sesepuh membawa sesaji dalam arakarakan tersebut dan menaburkan abu dari kemenyan di sepanjang jalan. Kemudian sesaji diletakkan di atas panggung yang diikuti oleh para sesepuh. Sesepuh Tiban sekaligus plandang dalam Tiban yang memimpin didahului dengan membaca doa di dekat sesaji. Plandang memberi banyu kembang kepada pelaku Tiban. Para tetua, penabuh dan plandang duduk melingkari sesaji. Hal ini merupakan upaya harmonisasi secara spiritual untuk menyelaraskan antara daya aura magis manusia dengan seluruh ciptaan Tuhan khususnya kekuatan alam dan makhluk gaib (Abimanyu 2014, 55).

Para sesepuh duduk mengelilingi sesaji dan plandang mulai melakukan slametan. Slametan dimulai dengan mengucapkan doa menurut agama Islam dari plandang. Slametan ini dilakukan agar seluruh warga desa purwokerto selamat dari marabahaya dengan cara berdoa kepada Tuhan Yang Maha Kuasa. Slametan menjadi ritus sederhana dengan membuat sesaji dan dikendurikan oleh masyarakat yang terkait dengan peringatan daurhidup (lifecycle), sumber-sumber kehidupan, terhadap alam supranatural, arwah leluhur/nenek moyang, dan ritus lain dengan tujuan keselamatan dan perlindungan manusia (Sumintarsih 2007, 139).

Ritual Tiban di dalam prosesnya memiliki inti sajian yang paling penting yang ditandai dengan dimulainya peTiban melakukan ritual Tiban. Para peTiban harus mengikuti peraturan yang dibuat. Misalnya, pemain harus bergantian memecut menggunakan lidi diambil dari pohon aren. Sasaran pecutan tidak sembarangan karena mereka dilarang memecut kaki dan kepala lawan. Para pemain harus mengikuti bunyi gamelan yang mengiringi acara. Meski mengalami banyak luka pecutan tapi para pelaku seolah tidak merasakan sakit. Mereka tetap bergembira dan mengikuti acara hingga selesai. Di akhir laga, plandhang meminta para pemain untuk berjabat tangan agar tidak ada dendam ataupun rasa permusuhan.

Jika masing-masing pelaku siap, maka iringan tetabuhan segera berbunyi tanda dimulainya Tiban. Dua orang pelandang, masing- masing menempati sisi yang berhadapan. Para pelaku tampil dan bersalaman. Plandang memberikan masing-masing pelaku sebuah pecut. Sekalipun sudah ada peraturan permainan yang sudah sama-sama diketahui, namun masih juga diperingatkan oleh plandhang bagian-bagian badan yang boleh dilecut dan yang tidak. Sasaran pecut ialah punggung dan badan bagian depan di atas pusar. Daerah larangan ialah bagian pusar ke bawah, dan kepala. Setelah dilakukan "sut" yaitu mengundi dengan mengadu jari untuk menentukan siapa yang melecut dulu, maka mulailah permainan.

Bertanding dengan para senior mempunyai ketertarikan tersendiri bagi para pemula, karena para senior biasanya menunggu waktu yang tepat untuk 
melakukan pecutan sesuai dengan harapan. Jika pecutan tepat sasaran seperti yang diharapkan makalawanakan mendapatkan luka atau mengeluarkan banyak darah. Jadi melakukan pecutan dalam Tiban ini tidak bisa sembarangan, harus mengetahui waktu dan posisi pas untuk melakukan pecutan. Setiap satu pecutan dari pelaku nantinya akan diarahkan oleh plandang sebagai isyarat pergantian giliran oleh lawan.

Proses ritual terakhir adalah penutup sajian yang ditandai dengan para pemain istirahat sejenak kemudian dilanjutkan dengan salam-salaman diiringi oleh doa. Para pelaku Tiban dan sesepuh membawa pecut yang sudah dipakai. Pelaku bersalaman dengan pelaku lain serta para sesepuh untuk mengakhiri ritual Tiban. Salam-salaman tersebut bertujuan agar tidak salah paham antara pemain satu dengan pemain dan antara pemain dengan wasit. Pada upacara penutupan ini pemuka adat atau sesepuh memimpin doa menurut agama Islam agar ritual yang telah teraksana mendapat restu dari Tuhan dan berharap air hujan turun.

Ritual mempunyai ketentuan sendiri bagi pelaksanaan. Mulai dari membuat sesajen sampai memakai beberapa alat yang diyakini dapat membantu proses dalam ritual. Ritual Tiban mempunyai syarat penting untuk terlaksana ritual. Syarat penting tersebut terdiri dari pelaku. Pelaku dalam Tiban tidak hanya peTiban atau orang awam atau bahkan tamu, plandhang Tiban, sesepuh dan pemusik bisa disebut sebagai pelaku Tiban. Para peTiban ini dari berbagai daerah seperti Trenggalek, Tulungagung, Blitar bahkan ada pelaku dari para penonton yang ingin ikut meramaikan Tiban tersebut. Pelaku Tiban hanya mengenakan celana dan tidak dianjurkan memakai baju atas. Ini bertujuan untuk memperlihatkan darah dari setiap pemain yang mana disebutkan bahwa darah melambangkan pengorbanan manusia demi kesejahteraan. Jumlah pelaku Tiban ada 60 orang, setiap pasang terdiri dari 2 pelaku. Semua pelaku Tiban adalah laki-laki dewasa sekitar umur 20-40 tahun. Hal ini disebabkan karena laki-laki dewasa berumur 20-40 tahun memiliki fisik kuat. Biasanya para pelaku Tiban bekerja sebagai petani karena Tiban sangat erat hubungannya dengan pertanian. Tugas plandang ialah memberi arahan kepada pelaku berapa kali pelaku harus memecut dan mengatur jalannya ritual Tiban.

\section{Tarian dalam Ritual Tiban}

Gerak tari dalam ritual Tiban berbeda dari tarian sehari-hari melainkan gerak tari dalam ritual Tiban diciptakan untuk Tiban sendiri. Tarian dalam ritual Tiban tidak mengalami perubahan bentuk sejak kemunculannya, perbedaanya adalah kekuatan masing-masing pelaku melakukan tarian dalam Tiban. Jika dahulu pelaku Tiban memecut dengan sekuat tenaga untuk menghasilkan darah yang banyak, sekarang pelaku memecut sesuai kekuatan mereka. Sekilas gerak yang dilakukan memang biasa dan terkesan hanya mengandalkan kekuatan otot saja, namun lebih dari itu gerak pelaku Tiban sengaja diciptakan khusus hanya pada peristiwa ritual Tiban saja. Segala sesuatu yang dimanifestasikan ke dalam gerak tari dipersepsikan dan melakukannya tidak pada keseharian (Langer 1988, 5),

Tarian dalam Tiban mempunya tiga pola dalam gerakan yang disebut ngoseg, kuda-kuda, dan mengacungkan pecut. Ngoseg yaitu posisi mempersiapkan diri. Posisi yang dimaksudkan adalah tubuh sedikit merendah, kaki direntangkan dan sedikit ditekuk. Begitu juga untuk posisi tangan pada tariannya. Kedua tangan direntangkan setengah dada dan tangan kanan memegang pecut, dilakukan hingga membentuk kuda-kuda yang sempurna. Tarian dalam Tiban dilakukan dengan cara menghentakan kedua kaki bergantian. Terakhir adalah pola mengacungkan pecut. Pola ini juga mempunyai persiapan sebelum melakukan pecutan-nya yaitu 
dengan cara pecut digenggam, cara menggenggam pecut seperti posisi tangan menaikkan bendera pada saat upacara. Setelah itu pecut diposisikan di depan dada lalu mulai memecut.

Dalam Tiban terdapat properti yang harus ada dan menjadi hal penting dalam ritual. Properti yang ada dalam ritual Tiban tersebut mempunyai makna demi tercapainya tujuan ritual, yaitu turunnya hujan demi kesejahteraan manusia terutama Desa Purwokerto, Kecamatan Ngadiluwih. Properti tersebut adalah pecut, pecut terbuat dari sada aren. Bahan ini mudah didapat karena daerahnya memang kaya akan pohon aren atau ini. Proses pembuatannya seikat lidi aren terdiri atas \pm 15 batang lidi yang terpilin menjadi satu. Di beberapa bagian diberikan suli, yaitu pengikat terbuat dari anyaman kulit pelepah aren itu sendiri, atau dari kulit bambu yang teranyam halus. Untuk satu Pecut diperlukan 3 ikat yang dipilin lagi menjadi satu, sehingga mendapatkan sebuah Pecut yang kuat, lentur, dilengkungkan tidak akan patah, dan dapat dilecutkan secepat kilat dengan mudah. Dari tengah sampai ujungnya dipasang simpul-simpul kecil dari potongan lidi sehingga Pecut itu pada bagian ujung tampak seperti kawat berduri.

Syarat ritual Tiban terakhir adalah musik. Menjelaskan musik Tiban secara umum dan menyebutkan instrumen dan repertoar lagu dalam ritual Tiban. Ritual Tiban terdapat berupa tetabuhan dari thonthongan, kendang, gambang, demung, saron, gong, kenong. Vokal dinyanyikan seorang laki-laki yang memiliki keterkaitan makna dengan gerak tari dalam Tiban. Sekitar tahun 2015 instrumen Tiban mulai tidak dipakai karena keterbatasan kemampuan penabuh yang bisa menguasai alat-alat tersebut. Instrumen yang sudah tidak digunakan adalah gambang, saron dan demung. Tetabuhan Tiban penting untuk memberi aba-aba dimulainya Tiban, jika pemain musik Tiban belum siap maka penari tidak akan mulai.

Kendhang semacam kendhang gedhe, (digunakan untuk mengiringi gendhinggendhing gedhe), maka suara tidak selantang yang berukuran lebih kecil. Instrumen thonthongan, terbuat dari seruas bambu diberi lubang di tengah- tengah diantara ruas bambu. Ketika memainkan thonthongan dipukul secara ritmis berupa motif berulang-ulang, tangan yang mahir mampu membuat suara bervariasi, terlebih lagi pada penggunaan dua thonthongan, sehingga hasil bunyi berbeda.

Dua thonthongan memiliki ukuran berbeda besar kecil, vokal yang dinyanyikan berupa lagu-lagu campursari atau lagu-lagu langgam yang sedang populer, lagu-lagu tersebut menyesuaikan selera masyarakat saat ini. Penyajian vokal untuk Tiban dibawakan kaum lakilaki. Lagu yang dinyanyikan ialah Kodok Ngorek, Blitar, dan lain-lain sebanyak tiga puluh jenis lagu. Kemudian, lagu Kodok Ngorek dan Blitar tersebut mengikuti minat masyarakat. Lagu yang sering dimainkan seperti, Yen Ing Tawang, Nyidam Sari, Caping Gunung, dan lain lain. Dari tetabuhan dan musik yang terdapat dalam ritual Tiban memiliki keterkaitan makna dan fungsi dengan gerak tari dalam Tiban.

\section{Sajian Musik dalam Ritual Tiban}

Musik dalam ritual Tiban ini adalah musik digunakan untuk prosesi ritual, musik Tiban mempunyai kedudukan penting saat terjadi ritual Tiban. Musik dalam ritual ritual tersebut tidak memiliki banyak instrumen dan terkesan sederhana, akan tetapi musik ini dapat dirasakan sebagai kekuatan ritual. Tanpa adanya musik, ritual tidak berlangsung. Pada tataran tertentu rasa musikal seseorang menjadi sebuah dasar yang menentukan seseorang tersebut memberikan respon berupa reaksi emosi terhadap musik yang ia dengar (Djohan 2010, 9)

Ritual Tiban tidak lepas dari musik 
yang menjadi syarat dalam Tiban. Untuk menganalisis dan mengetahui bagaimana musik pada ritual Tiban maka dilakukan analisis tentang instrumen dan reportoar. Analisis tentang keseluruhan instrumen yang terdapat dalam ritual Tiban serta menganalisis reportoar gending dalam Tiban. Analisis reportoar gending dilakukan dengan cara menyebutkan semua gending-gending yang terdapat dalam ritual Tiban. Setelah mengetahui analisis instrumen dan reportoar gending dalam Tiban. Dalam bentuk dijelaskan motif setiap instrumen yang digunakan dalam permainan musik Tiban.

Bentuk musik yang terdapat dalam ritual Tiban ini tidak memiliki berbagai macam motif seperti bentuk musik dalam gending-gending Jawa. Instrumen yang digunakan tidak seperangkat gamelan lengkap, tetapi hanya menggunakan kendang, kethuk, gong dan ditambah dengan thonthongan. Bentuk sajian ini juga tidak memiliki aturan khusus kapan akan suwuk dan berapa putaran yang dimainkan karena tabuhan dalam ritual ini sama dan diulang ulang. Cakepan yang digunakan juga dari berbagai lagu-lagu langgam dan campursari yang saat ini sedang populer.

Kendang adalah instrumen paling penting dalam musik Tiban, tanpa kendang, maka penyajian musik dalam ritual Tiban tidak akan berlangsung. Kendang adalah instrumen pembuka dalam musik yang nantinya akan diikuti oleh instrumen lainnya. Adapun motif pembuka untuk kendang sebagai berikut.

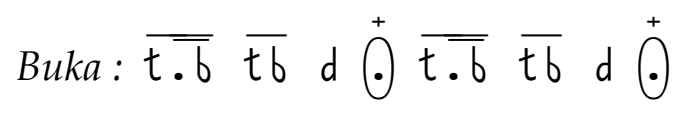

Kendang melakukan buka, instrumen yanglainmengikutialur denganmelakukan motif masing-masing. Motif buka hanya dilakukan satu kali saat mengawali jalan sajian musik. Motif kendangan yang diulang-ulang sebagai berikut:
Tangan kanan dalam Kendang :

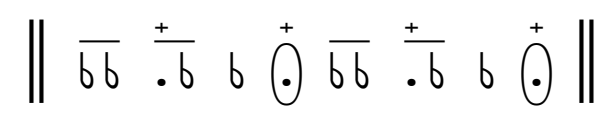

Tangan Kiri dalam Kendang :

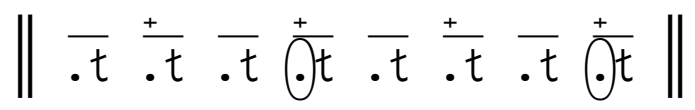

Motif kendangan yang diulang-ulang ini dimainkan sampai lagu dan penari selesai melakukan sajiannya. Motif terakhir kendangan pada musik Tiban yaitu suwuk. Suwuk menandakan berakhirnya setiap sajian lagu yang dimainkan. Motif suwuk hanya dimiliki kendang saja. Dalam suwuk tidak dilakukan sesegan yang biasanya dilakukan pada sajian-sajian karawitan Jawa. Biasanya motif suwuk dimainkan 2 kali sebelum berhenti. Adapun motif yang dimaksud sebagai berikut.

$$
\text { Suwuk: }\left\|\overline{d l} \frac{+}{d t} \overline{d b} \bigodot^{+}\right\|
$$

Jika kendang sudah melakukan motif suwuk maka motif di atas menandakan bahwa sajian musik selesai. Motif suwuk hanya dilakukan pada instrumen kendang. Karena kendang adalah penentu jalannya sajian maka ketika kendang melakukan suwuk instrumen lainnya akan mengikuti.

\section{Tabuhan pada}

$$
\text { kethuk: }\|+\cdot \Theta \cdot+\cdot \Theta\|
$$

Motif di atas akan diulang-ulang sampai penyajian musik Tiban berakhir. Motif kethuk yang diulang-ulang ini akan dimainkan setelah kendang melakukan motif buka. Motif kethuk ini tidak banyak memiliki motif-motif lain sehingga akan tertutup oleh kendang atau thonthongan.

$$
\begin{aligned}
& \text { Motif thonthongan 1: } \| \begin{array}{llll}
\overline{\mathrm{xx}} & \stackrel{+}{\cdot \mathrm{x}} & \mathrm{x} & \stackrel{+}{\mathrm{x}} \|
\end{array} \\
& \text { Motif thonthongan 2: }\|\overline{\cdot x} \cdot \overline{\cdot x} \cdot \overline{\cdot x} \cdot \overline{\cdot x}\|
\end{aligned}
$$


Thonthongan jika dimainkan secara bersamaan dalam motif satu dan motif dua akan terdengar seperti imbal.

Untuk mengetahui keseluruhan tabuhan dari instrumen dapat dilihat dalam transkip keseluruhan tabuhan langgam Caping Gunung Slendro sanga.

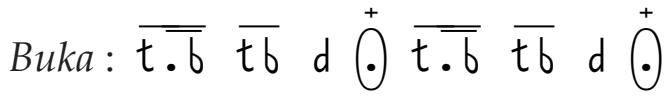

$K: \| \overline{b d} \overline{\cdot d} \overline{b t} \overline{\cdot t} \overline{b d} \overline{\cdot d} \overline{b t} \cdot \bar{t} \quad \overline{b d} \overline{\cdot d} \overline{b t} \overline{\cdot t} \overline{b d} \overline{\cdot d} \overline{b t} \cdot \bar{t}$

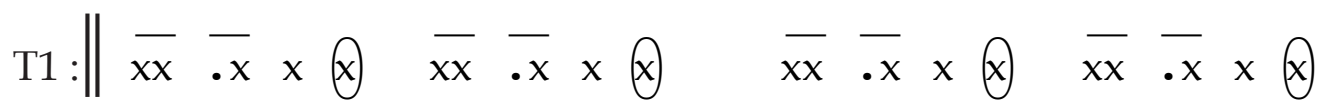

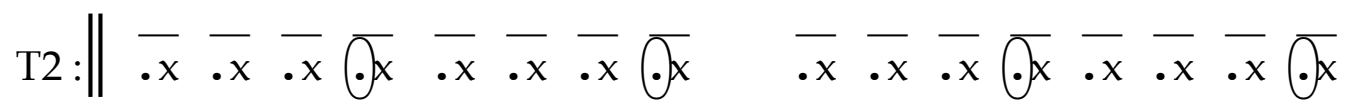

$\mathrm{KT}: \| \cdot{ }^{+} \cdot{ }^{+}+{ }^{+}$.

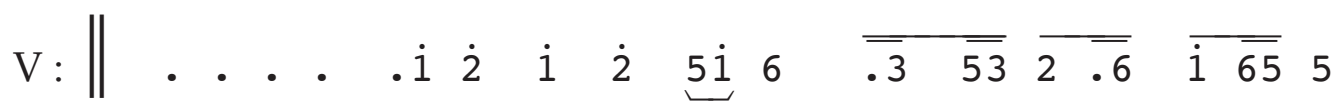

Dek ja - man ber ju ang njur kelingan a - nak lanang

$K: \overline{b d} \cdot \overline{\cdot d} \overline{b t} \cdot \bar{t} \overline{b d} \cdot \bar{b} \overline{b t} \cdot \bar{t} \quad \overline{b d} \overline{\cdot d} \overline{b t} \cdot \bar{t} \overline{b d} \cdot \bar{b} \overline{b t} \cdot \overline{(t}$

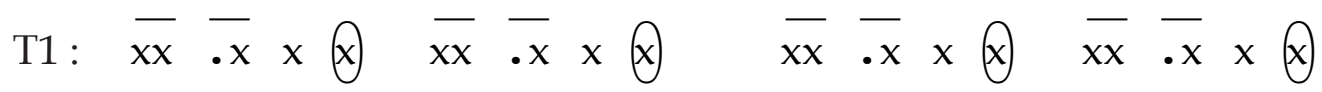

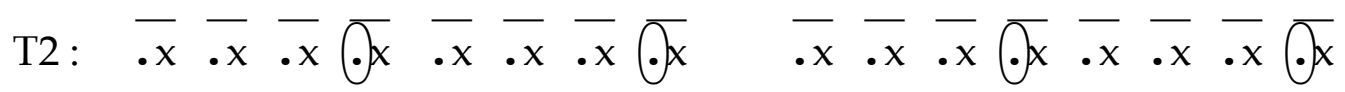

$\mathrm{KT}: \quad \cdot \quad \cdot \quad \cdot$

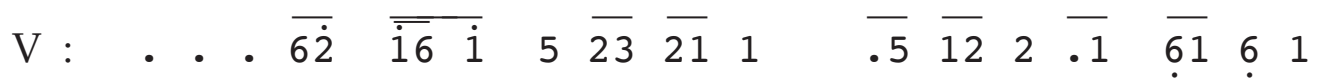

$\mathrm{Bi}$ - yen tak o pen i gek saiki a - na ngendi

$K: \overline{b d} \overline{\cdot d} \overline{b t} \cdot \bar{t} \overline{b d} \overline{\cdot d} \overline{b t} \cdot \bar{t} \quad \overline{b d} \overline{\cdot d} \overline{b t} \cdot \bar{t} \overline{b d} \overline{\cdot d} \overline{b t} \cdot \bar{t}$

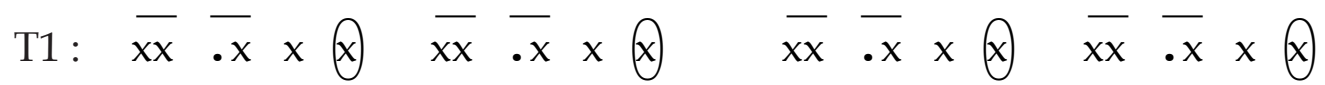

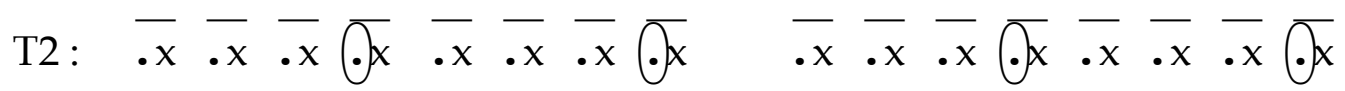


KT:

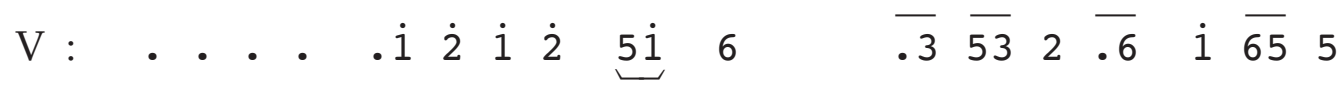

$$
\begin{aligned}
& \text { Ja re ne wes me - nang ke turut an sing di ga dang }
\end{aligned}
$$

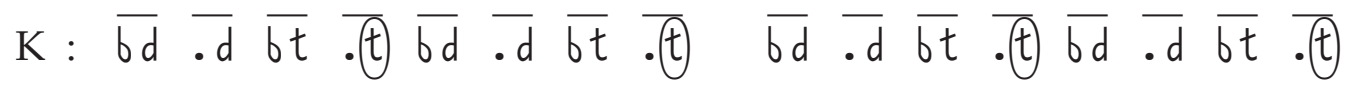

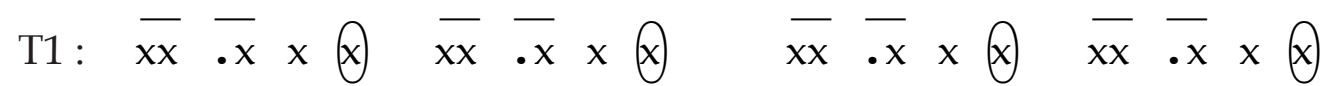

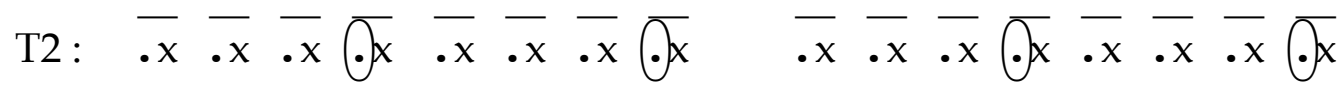

KT:

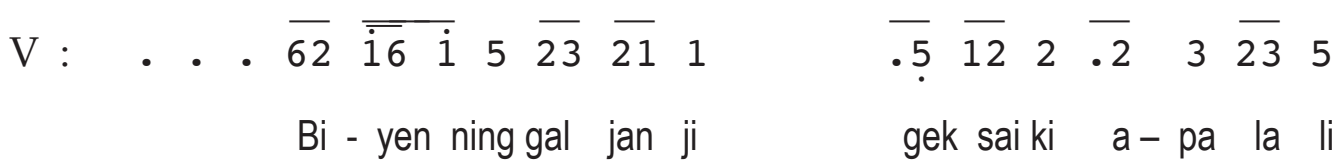

$K: \overline{b d} \cdot \overline{\cdot d} \overline{b t} \cdot \bar{t} \overline{b d} \cdot \bar{b} \overline{b t} \cdot \overline{\cdot t} \quad \overline{b d} \cdot \bar{b} \overline{b t} \cdot \bar{t} \overline{b d} \cdot \bar{b} \overline{b t} \cdot \bar{t}$

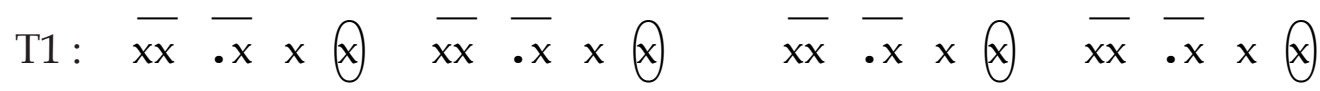

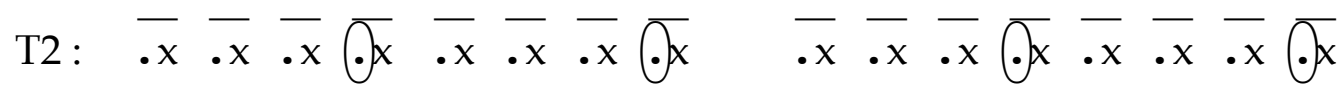

KT:

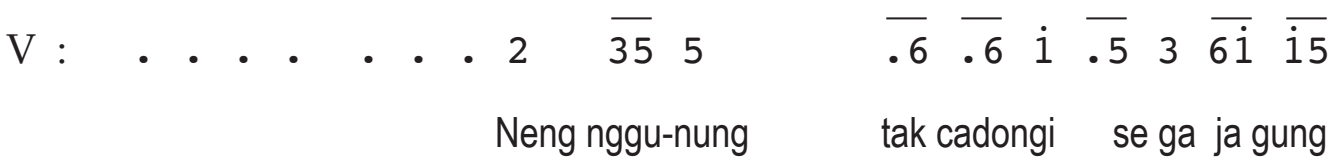

$K: \overline{b d} \cdot \overline{\cdot d} \overline{b t} \cdot \bar{t} \overline{b d} \cdot \bar{b} \overline{b t} \cdot \bar{t} \quad \overline{b d} \cdot \bar{b} \overline{b t} \cdot \bar{t} \overline{b d} \cdot \bar{b} \overline{b t} \cdot \bar{t}$

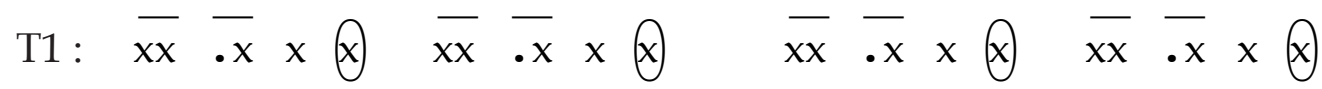

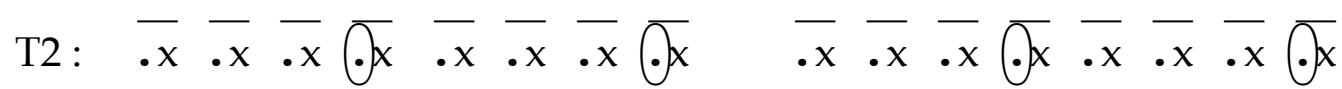


KT:

$\mathrm{V}: \quad . \quad . \quad . \quad . \quad 5 \overline{6 \overline{\mathrm{i}}} \mathrm{i}$

Yen mendung

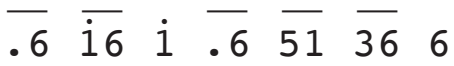

tak silihi ca-ping nggunung

$K: \overline{b d} \cdot \overline{\cdot d} \overline{b t} \cdot \overline{(t)} \overline{b d} \cdot \bar{b} \overline{b t} \cdot \bar{t} \quad \overline{b d} \overline{\cdot d} \overline{b t} \cdot \bar{t} \overline{b d} \cdot \bar{b} \overline{b t} \cdot \overline{(t}$

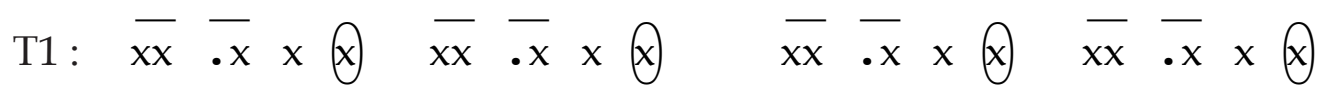

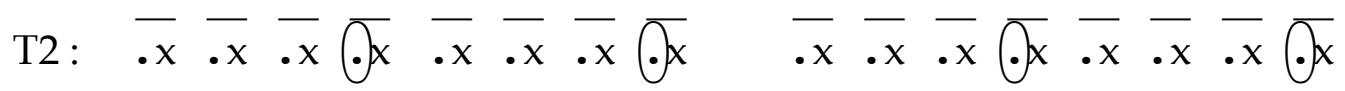

KT:

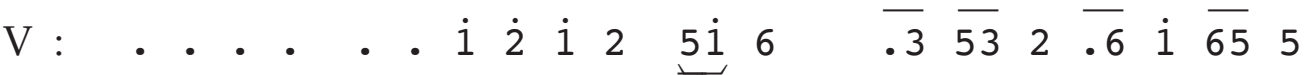

Su kor bi sa nyawang gunung de sa da di re ja

$K: \overline{b d} \overline{\cdot d} \overline{b t} \cdot \bar{t} \overline{b d} \overline{b d} \overline{b t} \overline{\cdot t} \overline{b d} \overline{\cdot d} \overline{b t} \overline{\cdot t} \overline{b d} \cdot \bar{b} \overline{b t} \cdot \bar{t} \|$

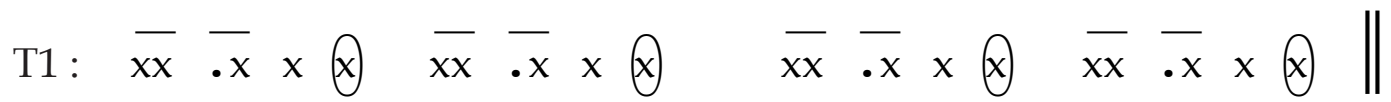

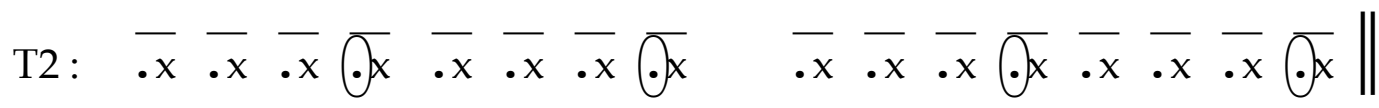

$\mathrm{KT}: \quad{ }^{+} \quad{ }^{+}{ }^{+}$.

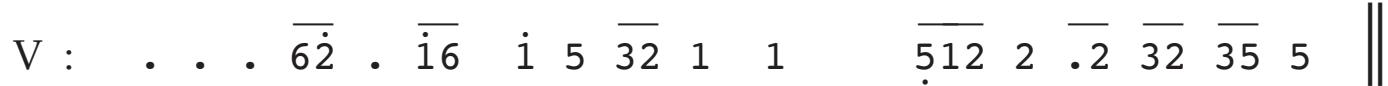

Be ne 0 ra i-lang nggon e pa da lara la pa

$K: \overline{b d} \overline{\cdot d} \overline{b t} \overline{\cdot t} \overline{b d} \overline{\cdot d} \overline{b t} \overline{\cdot t} \quad \overline{b d} \overline{\cdot d} \overline{b t} \overline{\cdot t} \overline{d l} \frac{+}{d t} \overline{d b} \bigodot_{0}^{+}$

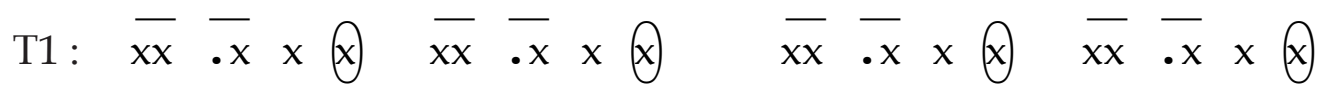

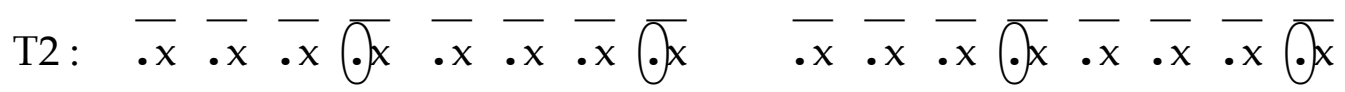

$\mathrm{KT}$ : 
Penggunaan musik Tiban tidak hanya untuk lagu yang mempunyai laras slendro sanga, akan tetapi bisa digunakan pada langgam yang memiliki laras pelog karena pada musik Tiban sendiri tidak ada ketentuan dalam permainannya.

Dari keseluruhan lagu dan instrumen memiliki jalan sajian yang sama yaitu buka kendang dan diikuti instrumen lainnya lalu diikuti vokal langgam yang akan dinyanyikan. Musik instrumen ritual Tiban berupa motif-motif di dalamnya dan digabung dengan vokal. Dalam keseluruhan lagu, motif yang digunakan setiap instrumennya sama, yang membedakan hanya dalam motif kendang yaitu mempunyai 3 motif. Dengan motif-motif instrumen tersebut dapat di aplikasikan dalam seluruh langgam. Dari pengaplikasian motif ke seluruh langgam dapat membentuk urutan sajian musik dalam ritual Tiban

\section{Fungsi Musik dalam Ritual Tiban}

Guna dan fungsi adalah dua hal yang berbeda karena keduanya memiliki hubungan dan kepentingan yang berbeda. Kebutuhan musik dalam ritual pertanda bahwa musik berfungsi dalam kegiatan manusia pada ritual tersebut. Fungsi musik memiliki hubungan-hubungan yang lebih luas dan spesifik. Pemikiran tersebut jika dihubungkan dengan musik, dalam hal ini musik dalam sebuah budaya, maka musik akan memiliki fungsi dan tujuan-tujuan kepada masyarakat pemilik musik tersebut (Merriam 1964). Dalam hal ini penggunaan menitikberatkan pada masalah situasi atau cara yang bagaimana musik itu digunakan, sedangkan function (fungsi) yang menitikberatkan pada alasan penggunaan atau tujuan musik itu mampu memenuhi kebutuhan manusia itu sendiri. Setelah melakukan riset di lapangan, 7 dari 10 fungsi yang dikemukakan Merriam berhubungan. Fungsi-fungsi tersebut berdasarkan dari pemahaman masyarakat
Desa Purwokerto sebagai pelaku ritual, para pemusik Tiban dan berdasarkan pengamatan yang didapatkan dilapangan. Sebagai tu juan dan akibat yang timbul dari penggunaan yang telah disebutkan di atas, maka dapat ditelusuri melalui fungsifungsi antara lain sebagai pengungkapan emosi, estetika, komunikasi, reaksi jasmani, pengesahan lembaga sosial dan upacara keagamaan, kesinambungan kebudayaan dan pengintegrasian masyarakat.

Pengungkapan emosi berkaitan dengan suatu pikiran dan perasaan yang khas, kondisi secara biologis dan psikologis, serta serangkaian kecenderungan untuk melakukan suatu tindakan tertentu (Goleman 1996). Fungsi pengungkapan emosional dalam musik berfungsi sebagai suatu media bagi seseorang untuk mengungkapkan perasaan atau emosinya. Berbagai ekspresi emosional yang muncul akibat musik menjadi suatu kesempatan untuk melepaskan gagasan atau pemikiran, semangar dan sesuatu yang dianggap sebagai 'ledakan' kreativitas oleh individu atau kelompok yang saling bersaing (Merriam 1964, 222-223). Pengekspresian pemain musik Tiban dengan instrumen yang di tabuh dan mengekspresikan emosi kepada penonton, sehingga penonton bisa ikut merasakan apa yang terjadi. Khususnya untuk pemain kendang, yang bisa membawa suasana musik terhadap pendengar. Penjelasan studi tentang jenis-jenis emosi, yang bisa didapat dari musik ritual Tiban adalah adanya emosi pemujaan. Hal ini dapat diketahui bahwa ritual Tiban adalah ritual memanggil hujan kepada yang Maha Kuasa dengan musik di dalamnya yang menjadikan musik Tiban dan petiban sebagai emosi pemujaan. Emosi tentang apresiasi estetika juga terdapat dalam musik Tiban. Ini ditandai dengan adanya motif-motif yang terdapat dalam instrumen musik Tiban. Emosi kegembiraan yang menggebugebu dibuktikan dengan adanya semangat para pemusik dalam memainkan masingmasing instrumen. Adanya jenis-jenis 
emosi menguatkan tentang bagaimana fungsi musik dalam hal emosional, khususnya pada ritual Tiban.

Keindahan atau estetika adalah suatu ilmu yang mempelajari segala sesuatu yang berkaitan dengan keindahan, mempelajari semua aspek yang disebut keindahan (Djelantik 1999, 7). Keindahan dapat dituangkan dalam bunyi-bunyian yang dihasilkan dari perpaduan instrumeninstrumen musik dalam ritual Tiban tertuang melalui pola permainan yang dapat dinikmati oleh pemusik itu sendiri maupun pendengarnya. Melalui musik kita dapat merasakan nilai-nilai keindahan baik melalui melodi atau dinamikanya. Estetika dalam ritual Tiban juga terdapat dalam musik dan instrumennya. Pola-pola dimaksud adalah motif setiap instrumen dalam ritual Tiban. Motif-motif setiap instrumen ritual Tiban menghasilkan bunyi-bunyian yang menghasilkan keindahan. Mulai dari kendangan dan instrumen thonthongan yang menjadikan musik dalam ritual Tiban mempunyai estetika tersendiri untuk peTiban maupun penonton.

Suatu budaya dapat lestari dan diwariskan kepada generasi penerus melalui proses komunikasi. Disini komunikasi berfungsi sebagai alat penyebaran tradisi dan nilai-nilai budaya yang dianut. Hal ini yang menjadikan komunikasi dan budaya adalah dua entitas yang tak terpisahkan (Larry A. Samovar, Porter, and McDaniel 2010, 16). Penyebaran tradisi ini juga terjadi dalam ritual Tiban. Ritual yang tidak hanya dilaksanakan di Desa Purwokerto saja melainkan di tempat-tempat lain di Tulungagung, Blitar maupun Treanggalek. Ritual ini diwariskan dari generasi ke generasi dan komunikasi adalah salah satu proses penyebaran ritual Tiban. Selain penyebaran tradisi dalam ritual Tiban, ritual Tiban juga mempunyai komunikasi pada setiap pelaku maupun instrumen yang terdapat dalam ritual Tiban.
Produksi respon fisik jelas merupakan fungsi penting dari musik. Musik sebagai reaksi jasmani diartikan jika sebuah musik dimainkan, musik itu dapat merangsang sel-sel saraf manusia, sehingga meyebabkan tubuh kita bergerak mengikuti irama musik tersebut. Jika musik tersebut lambat maka tubuh kita akan merasakan dan lebih menghayati dengan lagu tersebut. jika musik yang didengarkan cepat biasanya akan cenderung memberikan semangat. Dalam hal ini seseorang secara kompleks memproses, mengalami, dan merespon musik dengan integrasi sensorik, motorik, atensi, emosi dan proses memori (Münte, Altenmüller, and Jäncke 2002). Efektivitas dari awal sampai akhir ritual Tiban ada pemenggalan-suatu cerita dalam penyajiannya. Dari tempat yang berawal dari balai desa menuju tempat ritual yang dilakukan dengan cara arak-arakan memberikan efektivitas tersendiri untuk peTiban maupun pemusik. Penentuan waktu pelaksanaan ritual juga memiliki suatu efektivitas dalam respon jasmani. Sehingga dari tempat, waktu, tidak ada kejenuhan dalam sajian ritual.

Seni musik yang berada di Indonesia tidak bisa lepas oleh adanya hubungan yang erat dengan upacara adat di Indonesia ini. Pemanfaatan seni musik ini digunakan dalam upacara seperti perkawinan, kelahiran, kematian, serta upacara spiritual adat dan upacara kenegaraan. Di beberapa daerah penggunaan musik sebagai sarana upacara ini di yakini memiliki unsur magis, baik itu dari alat musik yang digunakan atau orang yang menyanyikan. Banyak contoh penggunaan musik terutama musik tradisional ini sebagai sarana upacara seperti halnya musik pada ritual Tiban. Ritual Tiban dijadikan untuk suatu kepercayaan.

Tiban sebagai ritual yang mentradisi karena dilakukan secara turun temurun baik masyarakatnya dari kelompok itu sendiri maupun masyarakat awam. Tiban memberikan banyak manfaat 
dalam kehidupan bermasyarakat selain sebagai bentuk peninggalan tradisional tetapi mampu menciptakan hubungan bermasyarakat yang harmonis dan mampu hidup berdampingan seperti yang tercipta dari adanya kekompakan antar sesama pemain dalam permainannya. Dalam hal ini musik berisi tentang ajaranajaran untuk meneruskan sebuah sistem dalam kebudayaan terhadap generasi berikutnya. Kebudayaan diwariskan secara turun temurun dari satu generasi ke generasi selanjutnya, dilakukan dengan proses belajar dan seleksi. Musik sebagai bagian dari kebudayaan masyarakat juga merupakan wahana pengajaran yang dapat menjamin kesinambungan dan stabilitas kebudayaan sampai generasi berikutnya (Merriam 1964, 204).

Setiap diadakan ritual, tidak hanya pelaku yang mengikuti jalannya sajian, tetapi perangkat desa seperti kepala desa, pemda dan pihak kepolosian turut mengikuti sepanjang jalannya sajian ritual Tiban. Definisi dari pengintegrasian sendiri merupakan sebuah sistem yang mengalami pembauran hingga menjadi suatu kesatuan yang utuh. Pada ritual Tiban seluruh elemen dapat terlibat di dalamnya, bahkan yang berkaitan dengan musik. Dalam hal ini seluruh mayarakat dapat saja mengamati dan mengikuti alur ritme musik di dalam ritual (Becker 1994; Salim 2018)

\section{Kesimpulan}

Desa Purwokerto mempunyai kepercayaan turun temurun yang hingga saat ini masih dilakukan oleh masyarakatnya. Salah satu kepercayaan mereka yaitu tentang adanya ritual yang dapat mendatangkan hujan yaitu ritual Tiban. Tiban dalam ritual mendatangkan hujan mempunyai hubungan dengan masyarakat yang menaunginya, bahwasanya keduanya saling berkesinambungan. Baik masyarakat membutuhkan Tiban untuk mendatangkan hujan serta Tiban membutuhkan masyarakat untuk menaunginya.

Bentukritual Tibanadalahmasyarakat menyiksa diri menggunakan pecut terbuat dari lidi aren yang dipintal dan masyarakat berjemur dipanas terik. Hal ini berfungsi untuk memanggil kekuatan supranatural yang mendatangkan hujan. Pelaksanaan ritual dimulai pada pukul 08.00 WIB hingga pukul 12.00 WIB. Pemilihan waktu tersebut dikarenakan pergantian waktu pagi ke siang dimana matahari mulai terik. Ritual Tiban dilaksanakan pada setiap 1 suro. Ritual Tiban mempunyai alur ritual mulai arak-arakan dari balai desa menuju arena tempat ritual berlangsung. Prasyarat ritual Tiban adalah adanya pelaku, baik petiban, sesepuh maupun pemain instrumen. Terdapat syarat gerak tari, tentu ritual Tiban mempunyai gerakan tarian dalam pelaksanaan ritual yaitu ngoseg, kudakuda, dan mengacungkan pecut. Terdapat syarat properti dalam ritual Tiban yaitu adanya pecut, busana, dan sesaji. Syarat terakhir dalam ritual Tiban adalah adanya musik yang menjadi bagian dalam ritual.

Instrumen dan Tabuhan musik yang mempunyai motif-motif tersendiri. Instrumen yang memiliki beberapa motif adalah kendang. Hal ni karena kendang adalah pemimpin jalannya sajian musik dalam ritual Tiban. Sebagai awalan ritual menggunakan buka kendang dan diikuti instrumen kethuk, gong, thonthongan, dan vokal. Setelah semua instrumen berbunyi, maka peTiban memulai ritual. Reportoar lagu yang digunakan dalam ritual ada 30 lagu mengikuti peserta yang terdiri dari 2 peTiban dalam satu lagu. Musik Tiban memiliki peran penting dalam prosesi ritual. Ketika musik dimainkan, maka semua pendengar akan terpengaruh oleh tabuhannya. Permainan musik sangat menunjang bagi ritual Tiban. Musik yang sederhana dan dinamis memberi kesan tersendiri kepada pemain Tiban. Penelitian ini menyimpulkan bahwa tanpa adanya musik, ritual Tiban tidak akan berjalan. 
Musik Tiban tidak hanya menjadi pengiring atau pelengkap saja melainkan musik mempunyai fungsi tersendiri dalam masyarakat maupun pelaku dan pelaksana dalam Tiban. Fungsi tersebut antara lain sebagai pengungkapan emosional, estetika, komunikasi, reaksi jasmani, pengesahan lembaga sosial dan upacara keagamaan, kesinambungan budaya, pengintegrasian masyarakat.

\section{Kepustakaan}

Abimanyu, Petir. 2014. Mistik Kejawen: Menguak Rahasia Hidup Orang Jawa. Jogjakarta: Palapa.

Becker, Judith. 1994. "Music and Trance." Leonardo Music Journal 4: 41-51.

Bruner, Edward M, and Victor W Turner. 1986. The Anthropology of Experience. Urbana and Chicago: University of Illinois Press.

Djelantik, A. M. 1999. Estetika Sebuah Pengantar. Bandung: Masyarakat Seni Pertunjukan Indonesia.

Djohan. 2010. Respon Emosi Musikal. Bandung: Lubuk Agung.

Geertz, Clifford. 1992. Tafsir Kebudayaan. Yogyakarta: Kanisius.

Goleman, D. 1996. Emotional Intelligence: Kecerdasan Emosional, Mengapa EI Lebih Penting Daripada IQ. Jakarta: Gramedia.

Ismail, Arifuddin. 2012. Agama Nelayan: Islam Lokal Di Tanah Mandar. Yogyakarta: Putaka Pelajar.

Kastolani, and Abdullah Yusuf. 2016. "Relasi Islam Dan Budaya Lokal (Studi Tentang Tradisi Nyadren Di Desa Sumogawe Kecamatan Getasan Kabupaten Semarang)." Kontemplasi 04 (01): 52.
Koentjaraningrat. 1990. Pengantar Ilmu Antropologi. Jakarta: Rineka Cipta.

- - - 1997. Pengantar Antropologi (PokokPokok Etnografi II). Jakarta: PT Rineka Cipta.

Langer, Suzanne K. 1988. Problematika Seni. Bandung: STSI Bandung.

Larry A. Samovar, Richard E. Porter, and Edwin R. McDaniel. 2010. Komunikasi Lintas Budaya: : Communication Betwen Culture. 7th ed. Jakarta: Salemba Humanika.

Merriam, Allan P. 1964. The Anthropology of Music. Evanston, Illinois: Northwestern University Press.

Münte, T. F., E. Altenmüller, and L. Jäncke. 2002. “The Musician's Brain as a Model of Neuroplasticity." Nature Reviews Neuroscience 3 (6): 473-78.

Salim, Muhammad Nur. 2018. “Keterikatan Antara Sajian Gending Dan Proses Pencapaian Ndadi Pada Pertunjukan Jathilan." Dewa Ruci: Jurnal Pengkajian Dan Penciptaan Seni 13 (2): 73-97. https://doi.org/10.33153/dewaruci. v13i2.2507.

Schechner, Richard. 1985. Betweeen Theatre and Anthropology. Philadelphia: University of Pennsylvania Press.

- - . 2002. Performance Studies An Introduction. London and New York: Routledge.

Sumardjo, Jacob. 2006. Estetika Paradoks. Bandung: Sunan Ambu Press.

Sumintarsih. 2007. “Dewi Sri Dalam Tradisi Jawa." Jantra II (3): 136-44.

Turner, V. 1969. The Ritual Process. London: Routledge and Kegan Paul. 